07

\title{
Нестационарный электрохимический отклик на прерывистую деформацию Портевена-Ле Шателье алюминий-магниевого сплава
}

\author{
(C) А.А. Шибков, А.А. Денисов, М.Ф. Гасанов, А.Е. Золотов, М.А. Желтов \\ Тамбовский государственный университет им. Г.Р. Державина, \\ Тамбов, Россия \\ E-mail: shibkov@tsu.tmb.ru
}

(Поступила в Редакцию 6 августа 2018 г.)

\begin{abstract}
Установлено, что эффект Портевена-Ле Шателье в алюминий-магниевом сплаве АМг6, деформируемом в водной среде, сопровождается прерывистым электрохимическим откликом - отрицательными скачками электродного потенциала образца, возникающими одновременно со скачками механического напряжения на кривой деформирования. Статистический и фрактальный анализ скачкообразной составляющей электродного потенциала свидетельствует о наличие долговременных корреляций в структуре электрохимического отклика, характерных для состояния самоорганизующейся критичности. Обсуждается возможный механизм возникновения скачков электродного потенциала, связанного с динамикой деформационных полос.
\end{abstract}

Экспериментальные исследования выполнены при частичной поддержке РНФ (проект № 18-19-00304), а статистический и фрактальный анализ данных измерения выполнен при поддержке РФФИ (проект № 16-08-00773). Работа выполнена на оборудовании ЦКП Тамбовского государственного университета им. Г.Р. Державина.

DOI: 10.21883/FTT.2019.02.47129.224

\section{1. Введение}

Многие алюминиевые авиационные сплавы проявляют механическую нестабильность, которая выражается в явлении прерывистого течения, известного как эффект Портевена-Ле Шателье (ПЛШ) [1]. Этот эффект связан со спонтанным формированием локальных областей высокоскоростной интенсивной пластической деформации, или так называемых полос макролокализованной деформации, которые негативно влияют на формуемость сплавов, ускоряют коррозию и могут вызвать внезапное разрушение при металлообработке и в условиях эксплуатации [2,3]. Формирование деформационных полос и соответственно скачков напряжения сопровождается эмиссией различных физических полей: теплового [4], акустического [5-8] и электромагнитного [9]. В настоящей работе обнаружено и исследовано явление „электрохимической эмиссии“ - дискретных скачков электродного потенциала алюминиевого сплава, деформируемого в условиях проявления эффекта ПЛШ в коррозионной среде - водном растворе бинарного электролита.

\section{2. Методика}

Как известно, на свежеобразованной поверхности (СОП) алюминия, контактирующего с водой (или водным раствором электролита), формируется двойной электрический слой (ДЭС), состоящий из растворенных гидратированных ионов $\mathrm{Al}^{3+}$ со стороны электролита и соответствующего избытка электронной плотности со стороны металла [10]. Абсолютную величину скачка потенциала в ДЭС на границе металл/электролит измерить невозможно, но можно оценить компенсационным методом эдс элемента, составленного из исследуемого электрода и электрода сравнения, потенциал которого стабилен [11]. Исследование скачкообразной составляющей электродного потенциала металла, демонстрирующего прерывистую деформацию, не требует точного измерения абсолютного значения этого потенциала, что в свою очередь делает произвольным выбор электрода сравнения. Важно, чтобы потенциал электрода сравнения отличался от потенциала алюминия и был стабилен за время деформационного скачка $(<1 \mathrm{~s})$. В качестве электрода сравнения в работе использовался хлор-серебряный электрод (марки ЭСР-10101), стандартный потенциал которого значительно отличается от стандартного потенциала алюминия: +0.222 и $-1.66 \mathrm{~V}$ при $25^{\circ} \mathrm{C}$, соответственно [11]. Для исследования прерывистой деформации ПЛШ методом, основанным на измерении скачкообразной составляющей электродного потенциала $\Delta E(t)$, важно установить: а) взаимосвязь средних амплитуд скачков электродного потенциала и деформационных скачков; б) статистическое распределение амплитуд скачков $\Delta E_{m}$ образца при его растяжении до полного разрушения с целью изучения явлений самоорганизации и хаоса прерывистой деформации ПЛШ.

Материалом исследования являлся промышленный алюминий-магниевый сплав АМг6 (6.15 wt.\% $\mathrm{Mg}$, 0.65 wt.\% Mn, 0.25 wt.\%, 0.21 wt.\% Fe). Плоские образцы в форме двухсторонних лопаток с размером рабочей части $6 \times 3 \times 0.5 \mathrm{~mm}$ вырезались из холоднокатаной полосы вдоль направления прокатки. Перед испытанием образцы отжигались при $450^{\circ} \mathrm{C}$ в течение $1 \mathrm{~h}$ c последующей закалкой на воздухе. Учитывая, что характерные времена развития полос и деформационных скачков в сплавах системы $\mathrm{Al}-\mathrm{Mg}-\mathrm{Mn}$ составляет 


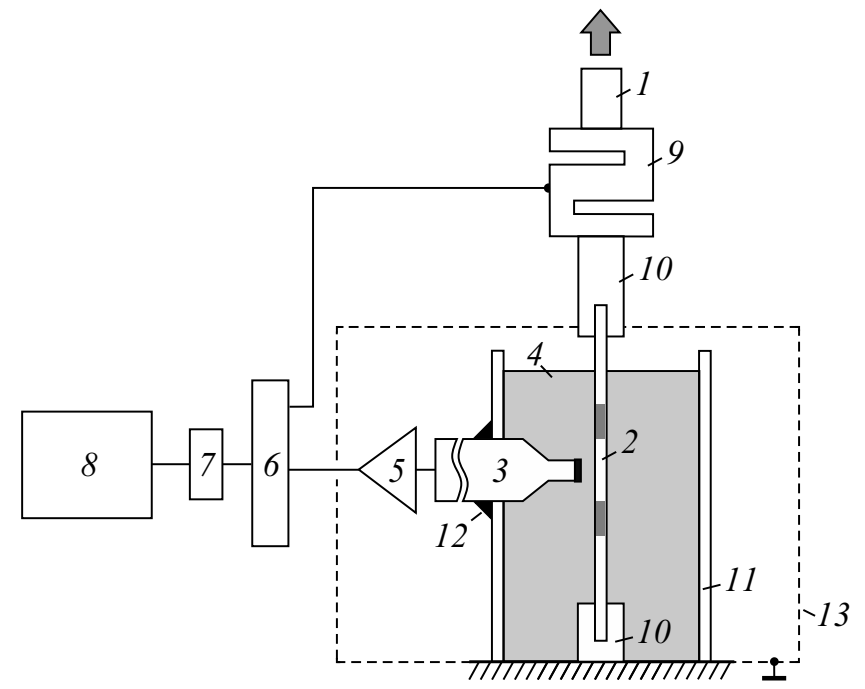

Рис. 1. Схема экспериментального устройства: 1 - шток испытательной машины, 2 - рабочая часть плоского образца, 3 - электрод сравнения, 4 - водный раствор электролита, 5 - импульсный предусилитель, 6 - коммутатор, 7 - АЦП, 8 - компьютер, 9 - датчик усилия, 10 - диэлектрические захваты, 11 - стеклянная кювета, 12 - герметик, 13 - экранирующий корпус.

$\sim 1-10 \mathrm{~ms}[12,13]$ в работе измерялась скачкообразная составляющая потенциала $\Delta E(t)$ деформируемого образца в водном растворе электролита с помощью импульсного предусилителя в полосе частот $10-10^{4} \mathrm{~Hz}$. Такой электрический канал регистрации фильтрует частоты изменения потенциала менее $\sim 10 \mathrm{~Hz}$ и, в частности, он отсеивает постоянную составляющую потенциала.

Схема электрохимической ячейки представлена на рис. 1. Электрохимическая ячейка представляет собой гальваническую цепь, состоящую из деформируемого растяжением в испытательной машине 1 плоского образца алюминий-магниевого сплава 2 , электрода сравнения 3, установленного на расстоянии $3 \mathrm{~mm}$ от поверхности образца, и водного раствора электролита 4 , в качестве которого использовали стандартный $3 \%$-ый водный раствор хлорида натрия. Канал регистрации электрического сигнала состоял из импульсного предусилителя 5 , коммутатора 6 , аналого-цифрового преобразователя (АЦП) 7 и компьютера 8. Растяжение образцов сплава АМг6 проводили в испытательной машине Instron (модель 3344) при комнатной температуре.

\section{3. Результаты и обсуждение}

\section{1. Скачки электродного потенциала в ходе деформирования в водном растворе электролита}

Сначала образец выдерживали в водном растворе электролита в течение около 20 минут до полной стабилизации (затухания дрейфа) электрического сигнала.
Затем образец деформировали одноосным растяжением со скоростью $\dot{\varepsilon}_{0}=3 \cdot 10^{-3} \mathrm{~s}^{-1}$ до разрушения. Типичная прерывистая кривая растяжения $\sigma(t)$ и скачкообразная составляющая электродного потенциала $\Delta E(t)$ показаны на рис. 2. Как видно, отрицательные скачки электродного потенциала сопровождают почти весь участок прерывистой деформации до разрушения образца. Средняя амплитуда скачков электродного потенциала за полное время деформирования составила около $4 \mathrm{mV}$ при среднеквадратичном шуме $\sim 0.1 \mathrm{mV}$.

Первый скачок механического напряжения на кривой деформации происходит при деформации $\varepsilon_{c}=14.7 \%$ (первая критическая деформация). С ростом деформации $\varepsilon$ амплитуда скачков напряжения возрастает от $\sim 1$ до $\sim 20 \mathrm{MPa} \mathrm{на} \mathrm{стадии} \mathrm{предразрушения.} \mathrm{В} \mathrm{то} \mathrm{же} \mathrm{время,}$ первый скачок электродного потенциала наблюдается при деформации около $16 \%$, когда амплитуда скачка напряжения достигает величины $\sim 3 \mathrm{MPa}$, т.е. на начальной стадии прерывистого течения, когда амплитуда скачков напряжения меняется в интервале 1-3 МРа, скачков потенциала не наблюдается.

При $\varepsilon>16 \%$ каждый скачок механического напряжения сопровождается отрицательным скачком элек-
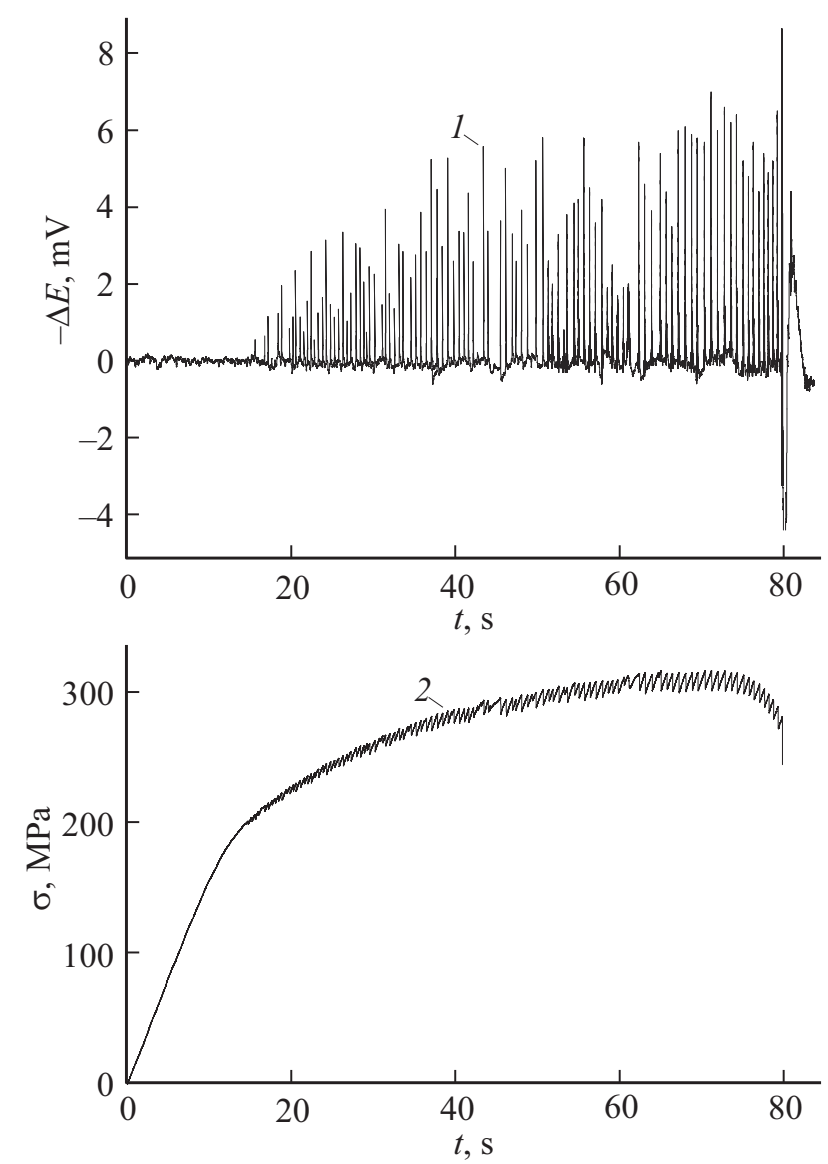

Рис. 2. Скачки электродного потенциала $\Delta E(1)$ в ходе прерывистой деформации ПЛШ образца сплава АМг6, отвечающие скачкам механического напряжения (2). Скорость деформирования $\dot{\varepsilon}_{0}=3 \cdot 10^{-3} \mathrm{~s}^{-1} . T=300 \mathrm{~K}$. Коррозионная среда $-3 \%$-ый водный раствор $\mathrm{NaCl}$. 

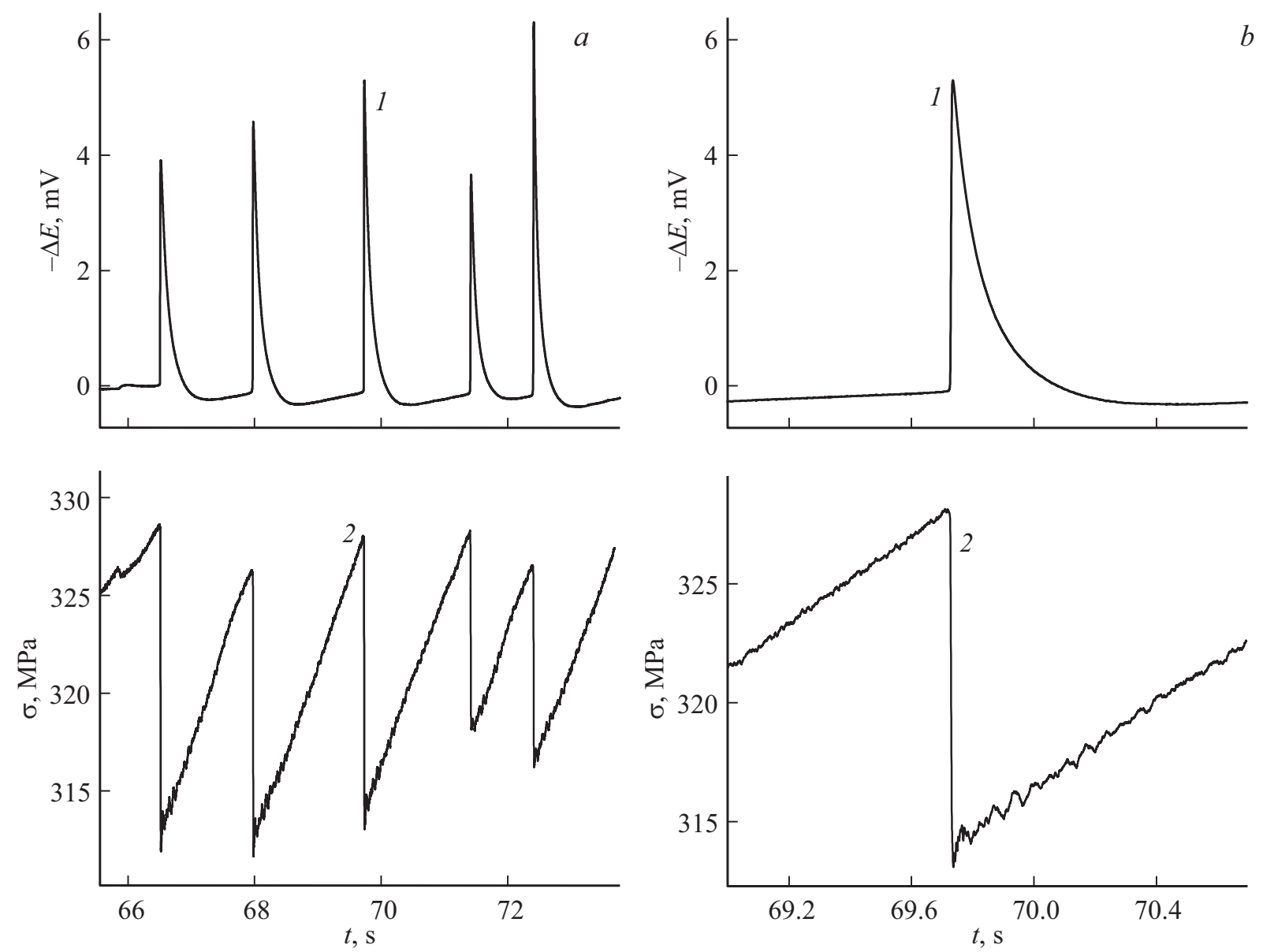

Рис. 3. $a-$ фрагмент записи сигналов $\Delta E(t)(1)$ и $\sigma(2)$ с более высоким временным разрешением; $b-$ отдельный скачок электродного потенциала $\Delta E(1)$ и напряжения $\sigma(2)$.

тродного потенциала, $-\Delta E(t)$ (см. рис. 2 и 3) синхронно с точностью до десятой доли миллисекунды. Характерное время фронта электрохимического сигнала составляет $\sim 1 \mathrm{~ms}$, а время спада порядка $\sim 50 \mathrm{~ms}$. C ростом деформирующего напряжения растет амплитуда скачков разгрузки и амплитуда скачков электродного потенциала так, что средние (текущие) значения этих величин связаны линейной зависимостью $\overline{\Delta E}_{m}=k\left(\overline{\Delta \sigma}_{m}-\Delta \sigma_{0}\right) \quad$ (рис. 4) с коэффициентом пропорциональности $k=0.3 \mathrm{mV} / \mathrm{MPa}, \Delta \sigma_{0} \approx 3.5 \mathrm{MPa}$. Это означает, что как и скачки механического напряжения, отрицательные скачки электродного потенциала характеризуют пластическую неустойчивость алюминиевого сплава при его деформировании в водной среде.

Отметим, что резкий отрицательный скачок электродного потенциала наблюдали в [14] в момент хрупкого разрушения стального стержня в $3 \%$-м водном растворе хлорида натрия. После разрушения стрежня электродный потенциал частично релаксирует в положительную сторону. Авторы $[14,15]$ полагают, что такое поведение электродного потенциала обусловлено образованием активной свежеобразованной поверхности (СОП) при разрыве образца, а затем ее пассивации вследствие образования защитной пленки. Измерения электродных потенциалов СОП различных металлов показали, что потенциал СОП гораздо отрицательнее потенциала исходной (окисленной) поверхности на ве-

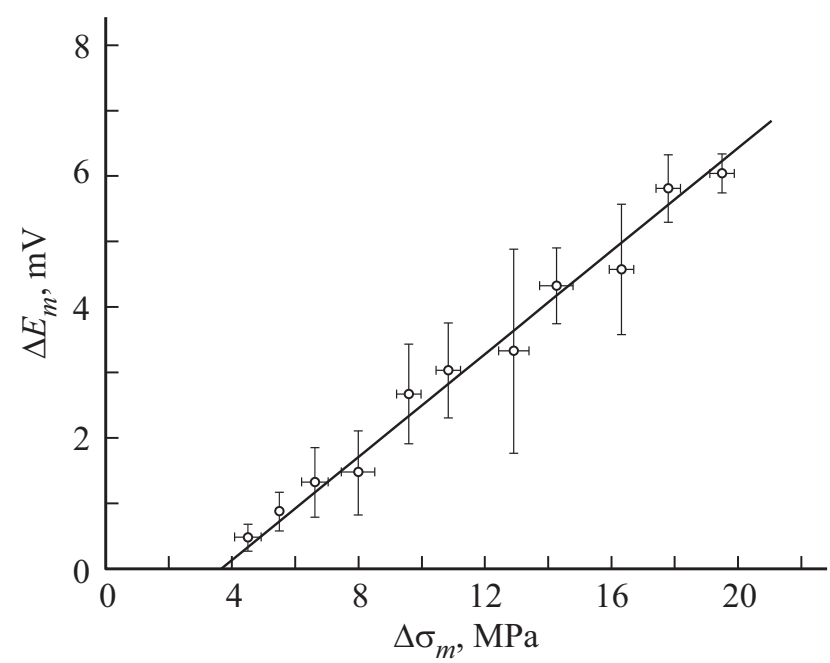

Рис. 4. Зависимость амплитуды скачка электродного потенциала $\Delta E_{m}$ от амплитуды скачка разгрузки $\Delta \sigma_{m}$ на кривой растяжения образца АМг6. 
личину $\sim 10-100 \mathrm{mV}[16]$. Согласно $[15,16]$, первоначально после образования СОП поверхность электрода находится в активном состоянии, оксидная пленка на ней отсутствует, в результате этого протекание анодного процесса на СОП максимально облегчено. Однако очень быстро на СОП вновь образуется пленка продуктов коррозии, которая представляет собой, как правило, гидроокись сложного состава, которая подавляет анодные процессы.

Естественно предположить, что качественно подобные электрохимические процессы происходят на поверхности алюминиевого сплава, который деформируется в водной среде в условиях проявления эффекта ПЛШ, который как известно, сопровождается формированием полос локализованной пластической деформации. Полосы ПЛШ представляет собой домены интенсивной деформации, скорость которой может достигать $\sim 10 \mathrm{~s}^{-1}$ [17], на 3-4 порядка превышающей среднюю по образцу. В данном случае образуется „частичная“ СОП в результате очень быстрого, за время не более $\sim 1 \mathrm{~ms}$, разрыва поверхностной оксидной пленки $\mathrm{Al}_{2} \mathrm{O}_{3}$, более хрупкой, чем алюминиевая матрица, в результате массового выхода на поверхность дислокаций полосы деформации. При этом образуется многочисленные поверхностные ступеньки, террасы, кинки и т. Д., которые существенно увеличивают скорость коррозионных процессов. В условиях контакта с водной средой выход на поверхность деформационной полосы запускает следующие коррозионные процессы:

- растворение активированного деформацией растяжения поверхностного слоя алюминиевого сплава, что вызывает резкий отрицательный скачок электродного потенциала вследствие формирования двойного слоя из гидратированных ионов $\mathrm{Al}^{3+}$ со стороны раствора и избытка электронов со стороны металла;

- формирование гальванопары, в которой анодом является СОП, образованная в результате выхода полосы на поверхность, а катодом - „старая““ поверхность, покрытая защитной пленкой, площадь которой значительно превышает площадь СОП;

- адсорбция водорода через СОП из водной среды; наводороженная область вблизи СОП может служить „затравкой“ для последующего водородного охрупчивания металла.

Таким образом, участок свежеобразованной и сильно деформированной поверхности металла, связанный с выходом деформационной полосы, является активным коррозионным центром в течение первых нескольких миллисекунд, пока на нем не сформирован новый оксидный слой. Скорость коррозионных процессов на сильно деформированной СОП, как известно $[18,19]$, может на несколько порядков превышать скорость коррозии на поверхности металла в отсутствии внутренних напряжений.

Следует отметить, что скачок электродного потенциала максимальной амплитуды (около $13 \mathrm{mV}$ ) наблюдается при разрыве образца, когда в течение нескольких микросекунд вскрывается максимально возможная площадь свежей поверхности алюминиевого сплава, свободной от защитной оксидной пленки. В то же время первые низкоамплитудные скачки разгрузки амплитудой от 1 до около $3 \mathrm{MPa}$ не сопровождаются скачками электродного потенциала, так как при столь низком уровне неустойчивости пластической деформации и, соответственно, локализации деформации, оксидная пленка, вероятно, не разрушается.

\section{2. Статистический и фрактальный анализ дискретного электрохимического отклика}

На рис. 5 представлены результаты статистического анализа амплитуд скачков электродного потенциала $s=\Delta E_{m}$. Как видно, форма гистограммы амплитуд скачков электродного потенциала близка к гиперболической. В двойных логарифмических координатах статистическая функция распределения $D(s)=N^{-1} d N / d s$ является приблизительно линейной с коэффициентом наклона к $s$-оси, равным -1.14 (см. вставку на рис. 5). Здесь $N-$ общее количество скачков, $d N-$ количество скачков, амплитуда которых попадает в узкий интервал $(s-\delta / 2$, $s+\delta / 2$, см. [20]). Это означает, что статистическая функция распределения подчинятся степенному закону

$$
D(s) \sim s^{-\alpha}
$$

с показателем степени $\alpha=1.14$.

Как известно, степенное распределение амплитуд лавин с показателем порядка единицы характерно для землетрясений (закон Гуттенберга-Рихтера [21]) и является одним из основных признаков состояния самоорганизующейся критичности (СОК). Другим свидетельством СОК является пространственно-временная монофрактальность системы. Фрактальную размерность временного ряда вычисляли, используя определение размерности Хаусдорфа-Безиковича [22]: $N(\varepsilon) \sim \varepsilon^{-D_{f}}$. На рис. 6

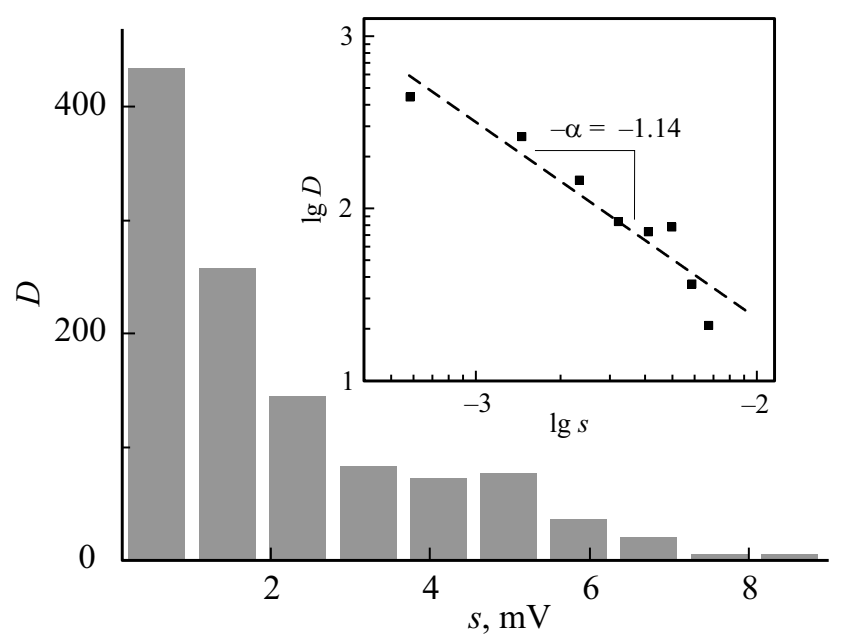

Рис. 5. Гистограмма $D(s)$ амплитуд скачков электродного потенциала $s\left(=\Delta E_{m}\right)$. На вставке гистограмма представлена в двойных логарифмических координатах. Линейная аппроксимация этой зависимости дает $\alpha=1.14$. 


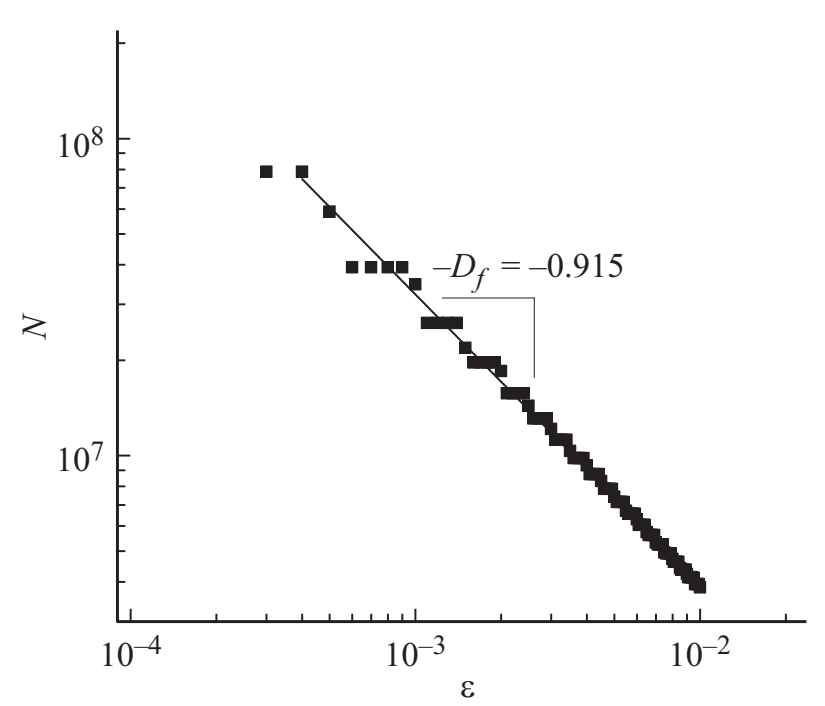

Рис. 6. Зависимость количества $N$ квадратов со стороной $\varepsilon$, от величины $\varepsilon$ в двойных логарифмических координатах. Линейная аппроксимация этой зависимости дает бокс-размерность $D_{f}=0.915$.

показана зависимость $N(\varepsilon)$ в двойных логарифмических координатах. Аппроксимация этой зависимости линейной функцией дает коэффициент наклона к $\varepsilon$-оси, равный - 0.915. Это означает, что бокс-размерность дискретного электрохимического отклика $D_{f}=0.915$. Таким образом, временной ряд $\Delta E(t)$ является фракталом со скейлингом не менее полтора порядка по $\varepsilon$ и по $N$, что является дополнительным признаком СОК.

Результаты статистического и фрактального анализа свидетельствуют о наличие долговременных скрытых корреляциях в дискретном отклике $\Delta E(t)$. К данному качественному выводу приводит и статистической анализ скачков напряжения в условиях эффекта ПЛШ в ряде металлических сплавов, в том числе в сплавах $\mathrm{Al}-\mathrm{Mg}$ [23,24]. Таким образом, мониторинг скачков электродного потенциала деформируемого в водной среде алюминиевого сплава позволяет контролировать и исследовать процессы самоорганизации статистического ансамбля коррозионных повреждений (деформационных полос, вышедших на поверхность) в отсутствии других методов. В [25] экспериментально установлено, что природа пространственной связи, обеспечивающей такую корреляцию связана с каскадным механизмом размножения деформационных полос, когда каждая полоса, за исключением первичной, зарождается на границе предшествующей полосы, обеспечивая эстафетную передачу скачкообразно распространяющейся макролокализованной деформации (дислокационной „лавины“) вдоль оси растяжения образца. Корреляционным полем являются локальные внутренние напряжения на фронте остановившейся границы деформационной полосы и дальнодействующие напряжения изгиба, возникающие вследствие того факта, что отдельные полосы переносят механический заряд, т.е. имеют избыток дислокаций одного механического знака (источник дальнодействующих напряжений [25]).

Полученные результаты могут быть использованы для разработки технологии непрерывного мониторинга и ранней диагностики деформационных полос в промышленных алюминиевых сплавах, демонстрирующих эффект Портевена-Ле Шателье, которые эксплуатируются в водной среде.

\section{4. Выводы}

1. Экспериментально установлено, что прерывистая деформация ПЛШ сплава АМг6, деформируемого в 3\%-ом водном растворе $\mathrm{NaCl}$, сопровождается прерывистым электрохимическим откликом - отрицательными скачками электродного потенциала образца амплитудой $\sim 1-10 \mathrm{mV}$, возникающих одновременно со скачками механического напряжения на кривой деформирования.

2. Проведен статистический и фрактальный анализ дискретного электрохимического отклика сплава АМг6, деформируемого в водной среде в условиях проявления эффекта ПЛШ. Установлено, что временной ряд $\Delta E(t)$ является фракталом со скейлингом не менее полутора порядков и фрактальной размерностью $D_{f}=0.915$, а статистическая функция распределения амплитуд скачков электродного потенциала подчиняется степенному закону с показателем степени -1.14 . Полученные результаты свидетельствуют о наличии долговременных корреляций, характерных для состояния самоорганизующейся критичности, что подтверждается литературными данными, полученными другими методами.

\section{Список литературы}

[1] Дж.Ф. Белл Экспериментальные основы механики деформируемых твердых тел. Наука, М. (1984). Ч. 2. 432 с.

[2] K. Chihab, Y. Estrin, L.P. Kubin, J. Vergnol. Scr. Met. 21, 203 (1987).

[3] А.А. Шибков, А.Е. Золотов, Д.В. Михлик, М.А. Желтов, А.В. Шуклинов, В.А. Аверков, А.А. Денисов. Деформация и разрушение материалов 8, 23 (2009).

[4] М.М. Криштал. МиТОМ 4, 26 (2003).

[5] F. Chmelik, A. Ziegenbein, H. Neuhauser, P. Lukac. Mater. Sci. Eng. A 324, 200 (2002).

[6] А.А. Шибков, А.Е. Золотов, М.А. Желтов. ФТТ 52, 2223 (2010).

[7] А.А. Шибков, А.Е. Золотов. Кристаллография 56, 147 (2011).

[8] А.А. Шибков, М.А. Желтов, М.Ф. Гасанов, А.Е. Золотов. ФTT 59, 2363 (2017).

[9] А.А. Шибков, С.А. Титов, М.А. Желтов, М.Ф. Гасанов, А.Е. Золотов, К.А. Проскуряков, А.О. Жигачев. ФТТ 58, 3 (2016).

[10] Ch. Vargel. Corrosion of aluminium. Elsevier Ltd. (2004). $658 \mathrm{p}$.

[11] А.Н. Фрумкин, В.Н. Андреев, Л.И. Богуславский. Двойной слой и электродная кинетика. Наука, М. (1981). 376 с. 
[12] W. Tong, H. Tao, N. Zhang, L.G. Hector. Scr. Mater. 53, 87 (2005).

[13] G.F. Xiang, Q.C. Zhang, H.W. Liu, X.P. Wu, X.Y. Ju. Scr. Mater. 56, 721 (2007).

[14] Л.Н. Петров. Коррозия под напряжением. Высш. шк., Киев (1986). $142 \mathrm{c}$.

[15] Л.Н. Петров, Н.Г. Сопрунюк. Коррозионно-механическое разрушение металлов и сплавов. Наук. думка, Киев (1991). $216 \mathrm{c}$.

[16] И.Л. Розенфельд, К.И. Афанасьев, В.А. Маричев. Физ.-хим. механика материалов 6, 48 (1980).

[17] H. Ait-Amokhtar, S. Bondrahem, C. Fressegeas. Scripta Mater. 54, 2113 (2006).

[18] Г.В. Карпенко, Э.М. Гутман, И.Е. Замостяник, Л.М. Гавриленко. Физ.-хим. механика материалов 3, 280 (1969).

[19] Г.В. Карпенко, И.Е. Замостяник, Э.М. Гутман. Физ.-хим. механика материалов. 1, 3 (1970).

[20] T.A. Lebedkina, M.A. Lebyodkin. Acta Mater. 56, 5567 (2008).

[21] B. Gutenberg, C.F. Richter. Ann. Geophis. 9, 1 (1956).

[22] Е. Федер. Фракталы. Мир, М. (1991). 230 с.

[23] M. Lebedkin, L. Dunin-Barkovsky, Y. Brechet, L. Kubin, Y. Estrin. Mat. Sci. Eng. A. 234-236, 115 (1997).

[24] М.А. Лебедкин. Самоорганизация и коллективные эффекты при неустойчивой пластической деформации кристаллов. Автореф. докт. дис. Черноголовка. ИФТТ РАН (2002). $197 \mathrm{c}$.

[25] А.А. Шибков, А.Е. Золотов, М.А. Желтов. Изв. РАН. Сер. физ. 76, 97 (2012).

Редактор Т.Н. Василевская 